\title{
Correction to: A system framework of model quality analysis for product model in collaborative manufacturing
}

Wei Yang ${ }^{1} \cdot$ Qing Zhao ${ }^{1} \cdot$ Xiaoguang Yan ${ }^{1} \cdot$ Zhuoning Chen $^{1}$

Published online: 12 October 2021

(C) Springer-Verlag London Ltd., part of Springer Nature 2021

\section{Correction to: The International Journal of Advanced Manufacturing Technology} https://doi.org/10.1007/s00170-021-07622-1

The original article contained a mistake.

Because the program number "SQ2019YFB170027" in the Funding information (before the Reference) of the paper is only used in the application stage, we request that the number be changed to the official number of this program "2019YFB1704300". We appologize for any inconvinience caused to editor team and readers.

The original article has been corrected.

Publisher's note Springer Nature remains neutral with regard to jurisdictional claims in published maps and institutional affiliations.

The online version of the original article can be found at https://doi.org/ 10.1007/s00170-021-07622-1

Zhuoning Chen

znchen@hust.edu.cn

1 School of Mechanical Science and Engineering, Huazhong, University of Science and Technology, Wuhan 430074, China 